Serum antibody response to Chlamydia trachomatis TroA and HtrA in women with tubal factor infertility

\title{
Rantsi, T.
}

2018-08

Rantsi , T , Joki-Korpela , P , Hokynar , K, Kalliala , I, Öhman , H, Surcel , H-M , Paavonen , J , Tiitinen , A \& Puolakkainen , M 2018 , ' Serum antibody response to Chlamydia trachomatis TroA and HtrA in women with tubal factor infertility ' , European Journal of

Clinical Microbiology \& Infectious Diseases, vol. 37 , no. 8 , pp. 1499-1502 . https://doi.org/10.1007/s10096-018-327

http://hdl.handle.net/10138/303671

https://doi.org/10.1007/s10096-018-3276-9

publishedVersion

Downloaded from Helda, University of Helsinki institutional repository.

This is an electronic reprint of the original article.

This reprint may differ from the original in pagination and typographic detail.

Please cite the original version. 


\title{
Serum antibody response to Chlamydia trachomatis TroA and HtrA in women with tubal factor infertility
}

\author{
T. Rantsi ${ }^{1}$ (D) P. Joki-Korpela ${ }^{1} \cdot$ K. Hokynar ${ }^{2} \cdot$ I. Kalliala ${ }^{1,3} \cdot$ H. Öhman ${ }^{4} \cdot$ H-M. Surcel ${ }^{4,5} \cdot$ J. Paavonen ${ }^{1} \cdot$ A. Tiitinen ${ }^{1}$. \\ M. Puolakkainen ${ }^{2}$
}

Received: 19 March 2018 / Accepted: 9 May 2018 / Published online: 18 May 2018

(C) Springer-Verlag GmbH Germany, part of Springer Nature 2018

\begin{abstract}
Persistent genital chlamydial infection may lead to tubal factor infertility (TFI). Chlamydia trachomatis TroA and HtrA are proteins expressed during persistent chlamydial infection in vitro. We studied serum IgG antibody response against these proteins by EIA in women with TFI and in subfertile women without tubal pathology. Altogether, 22 of 258 subfertile women (8.5\%) had TFI which was unilateral in 17 cases and bilateral in 5 cases. Overall, 55 (21.3\%) of the 258 women had TroA and 39 (15.1\%) had HtrA antibodies. Seropositivity to TroA and HtrA was more common among women with TFI than women with other causes for subfertility $(45.5$ vs. $19.1 \%, p=0.004$ for TroA; 36.4 vs. $13.1 \%, p=0.004$ for HtrA). Mean absorbance values and the prevalence of TroA and HtrA antibodies increased with increasing severity of TFI. On the basis of our results, TroA and HtrA serology has the potential to be further developed to a specific biomarker for C. trachomatis-related TFI.
\end{abstract}

Keywords Chlamydia trachomatis $\cdot$ Persistent infection $\cdot \operatorname{TroA} \cdot \mathrm{HtrA} \cdot$ Serology $\cdot$ Tubal factor infertility

\section{Introduction}

Chlamydia trachomatis is the causative pathogen of the most prevalent bacterial sexually transmitted infection worldwide [1]. The majority of infected women have uncomplicated lower genital tract infection, while some women develop persistent or ascending chlamydial infection [2]. This may lead to scarring of Fallopian tubes predisposing to tubal factor infertility (TFI) and ectopic

T. Rantsi

tiina.rantsi@hus.fi

1 The Department of Obstetrics and Gynecology, University of Helsinki and Helsinki University Hospital, Helsinki, Finland

2 Virology and Immunology, University of Helsinki and Helsinki University Hospital, Helsinki, Finland

3 Department of Surgery and Cancer, Institute of Reproductive and Developmental Biology, Faculty of Medicine, Imperial College, London, UK

4 National Institute for Health and Welfare, Helsinki, Finland

5 Faculty of Medicine, University of Oulu, Oulu, Finland pregnancy (EP). C. trachomatis $\mathrm{IgG}$ antibody test has been introduced as a screening test for TFI in subfertile women [3], but the presence of serum chlamydial antibodies indicates only exposure to the pathogen and cannot discriminate past immunity from persistent infection. More accurate methods for TFI evaluation are needed.

In vitro studies have shown that under stressful growth conditions, C. trachomatis can transform into a persistent form characterized by incomplete developmental cycle and altered gene transcription profile [4]. $\operatorname{Tro} \mathrm{A}(\mathrm{Y} \operatorname{tg} \mathrm{A})$ is a substrate binding protein in the iron transport system of $C$. trachomatis. The expression of TroA increases when the bacterium is cultured under iron starvation conditions [5]. High temperature requirement protein $(\mathrm{HtrA})$ is a highly conserved serine protease and has an essential role during $C$. trachomatis replication [6]. HtrA concentration increases when $C$. trachomatis is cultivated in the presence of penicillin [7]. In our previous study, we concluded that TroA and HtrA could be potential biomarkers for ascending and repeated $C$. trachomatis infection [8]. The aim of our present study was to investigate the presence of serum IgG antibodies to $C$. trachomatis TroA and HtrA among subfertile women with TFI. 


\section{Materials and methods}

\section{Study population}

Our study population consisted of 258 women referred for infertility to Helsinki University Hospital during July 2007 December 2010. Infertility work-up was performed according to the clinic's routine protocol after at least 1 year of unprotected intercourse. Tubal patency was evaluated either by hysterosalpingosonography (HSSG) or by laparoscopy (Fig. 1). TFI was defined as an occlusion of at least one tube. Cases with EP before or during infertility evaluation $(n=11)$ were included in the unilateral TFI group. Subfertile women with another etiology for subfertility, such as ovulatory disorder $(n=69)$, endometriosis $(n=37)$, male factor infertility $(n=25)$, unexplained infertility $(n=96)$, or other sporadic cause (hormonal disorder, structural anomaly, or pelvic adhesions due to previous pelvic surgery; $n=9$ ), served as the reference group. First-void urine or cervical swab specimen was collected for diagnosis of $C$. trachomatis by the nucleic acid amplification test (NAAT) [9].

\section{Serological methods}

Serum samples for the serological analysis were collected at the first outpatient clinic visit and stored at $-20{ }^{\circ} \mathrm{C}$ until analyzed. IgG antibody responses to the recombinant TroA and

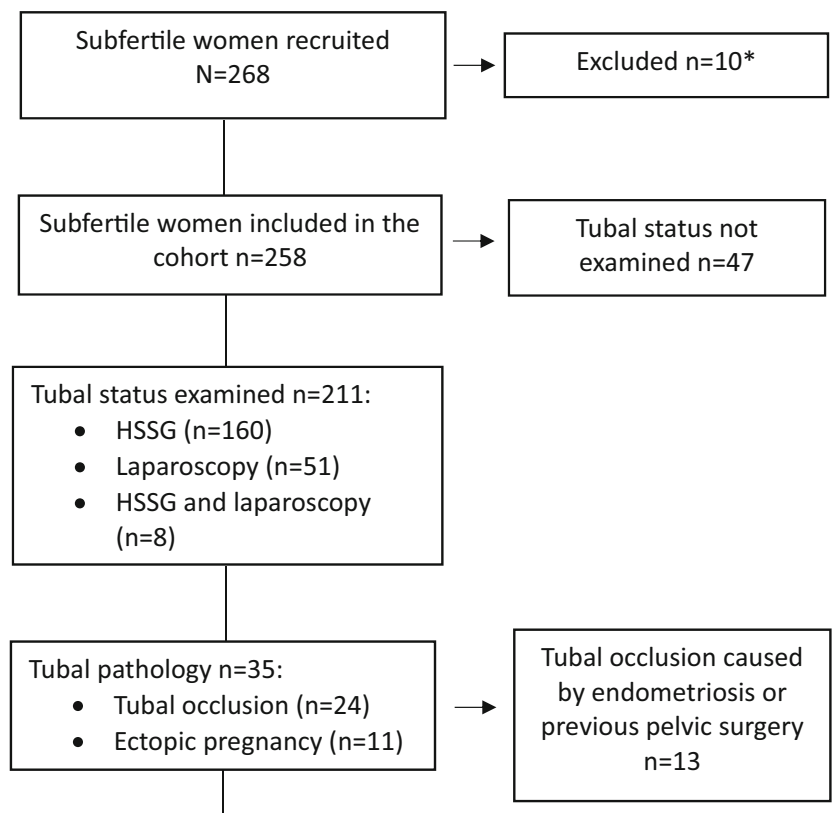

Tubal factor infertility $\mathbf{n}=\mathbf{2 2}$

Fig. 1 Flow chart of the study population. *Ten women were excluded for the following reasons: not meeting the criteria for infertility investigation $(n=5)$, not willing to have infertility investigation $(n=2)$, or referred directly to IVF from another clinic $(n=3)$
HtrA were analyzed by enzyme immune assay (EIA) as described in detail earlier [8]. The cutoff values were based on the absorbance values (mean $+2 \mathrm{SD}$ ) obtained using specimens of sexually inexperienced girls not exposed to $C$. trachomatis and were set as $\mathrm{A}_{450 \mathrm{~nm}} 0.5$.

Sera were also studied by microimmunofluorescence test (MIF). MIF serology was performed using purified elementary bodies (EB) of C. trachomatis and Chlamydophila pneumoniae as antigen [10]. MIF titers were classified as high $(\geq 128)$ or low $(\leq 64)$.

\section{Statistical methods}

Chi-squared test was used for the analysis of categorical data. Continuous variables were compared by the MannWhitney $U$ test as appropriate. Correlations between MIF titers and ranked EIA absorbance values were analyzed by Spearman's correlation coefficient and levels at $\leq 0.01$ were considered statistically significant. All statistical analyses were performed by IBM SPSS Statistics 22.0 (IBM Corp., Armonk, NY) and STATA version 13 (StataCorp. Stata Statistical Software: Release 13. College Station, TX: StataCorp LP. 2013).

\section{Results}

\section{The baseline characteristics}

Altogether, 22 (8.5\%) of the 258 subfertile women had TFI. Of those, bilateral tubal occlusion was found in five women and unilateral tubal occlusion in 17 women (Fig. 1). At the time of serum sampling, none had positive $C$. trachomatis nucleic acid amplification test (NAAT) from the urogenital sample. The baseline characteristics by the presence of $C$. trachomatis TroA and HtrA IgG are presented in Table 1.

\section{C. trachomatis TroA, HtrA, and MIF antibodies}

Of the 258 women, 55 (21.3\%) had TroA IgG antibodies and $39(15.1 \%)$ had HtrA IgG antibodies. Seropositivity to TroA and HtrA was more common among women with TFI than in women with other causes for subfertility ( $45.5 \mathrm{vs.} 19.1 \%, p=$ 0.004 for TroA; 36.4 vs. $13.1 \%, p=0.004$ for HtrA). TroA and HtrA antibody levels were highest in women with bilateral TFI (mean $\mathrm{A}_{450 \mathrm{~nm}} 1.784$ for TroA and 1.746 for HtrA) compared to women with unilateral TFI (mean $\mathrm{A}_{450 \mathrm{~nm}} 0.663$ for TroA and 0.539 for HtrA) or subfertile controls (mean $\mathrm{A}_{450 \mathrm{~nm}} 0.392$ for TroA and 0.306 for HtrA). Seroprevalence rates of TroA and HtrA increased with increasing severity of tubal damage (Fig. 2).

Of the women with high MIF titers $(\geq 128), 75.0 \%$ were TroA antibody positive and $58.3 \%$ were HtrA antibody 
Table 1 The baseline characteristics of the study population

\begin{tabular}{|c|c|c|c|c|c|c|}
\hline \multirow[t]{2}{*}{ Characteristic } & \multicolumn{3}{|l|}{ TroA IgG antibody } & \multicolumn{3}{|l|}{ HtrA IgG antibody } \\
\hline & Positive $(N=55)$ & Negative $(N=203)$ & $p$ value & Positive $(N=39)$ & Negative $(N=219)$ & $p$ value \\
\hline \multicolumn{7}{|l|}{ Age in years } \\
\hline Mean (SD, range) & $32.2(4.0,21.9-39.2)$ & $31.1(4.1,20.6-40.0)$ & \multirow[t]{2}{*}{0.13} & $31.7(4.0,21.8-38.9)$ & $31.2(4.2,20.6-40.0)$ & \multirow[t]{2}{*}{0.57} \\
\hline Median & 31.6 & 31.2 & & 31.4 & 31.3 & \\
\hline \multicolumn{7}{|l|}{ Smoking $(n, \%) *$} \\
\hline Current smoker & $9(17.3)$ & $36(18.0)$ & \multirow[t]{2}{*}{0.91} & $8(20.5)$ & $37(17.4)$ & \multirow[t]{2}{*}{0.64} \\
\hline Non-smoker & $43(82.7)$ & $164(82.0)$ & & $31(79.5)$ & $176(82.6)$ & \\
\hline \multicolumn{7}{|c|}{ History of C. trachomatis infection $(n, \%)^{* *}$} \\
\hline Yes & $18(33.3)$ & $19(9.5)$ & \multirow[t]{2}{*}{$<0.001$} & $11(28.2)$ & $26(12.1)$ & \multirow[t]{2}{*}{0.009} \\
\hline No & $36(66.7)$ & $181(90.5)$ & & $28(71.8)$ & $189(87.9)$ & \\
\hline \multicolumn{7}{|c|}{ Duration of infertility in years } \\
\hline Mean (SD, range) & $2.0(1.3,1.0-9.0)$ & $1.8(1.3,0.5-10.0)$ & \multirow[t]{2}{*}{0.06} & $2.0(1.3,1.0-9.0)$ & $1.9(1.3,0.5-10.0)$ & \multirow[t]{2}{*}{0.29} \\
\hline Median & 1.5 & 1.5 & & 1.5 & 1.5 & \\
\hline \multicolumn{7}{|c|}{ Type of infertility $(n, \%)$} \\
\hline Primary & $30(54.5)$ & $152(74.9)$ & \multirow[t]{2}{*}{0.003} & $24(61.5)$ & $158(72.1)$ & \multirow[t]{2}{*}{0.18} \\
\hline Secondary*** & $25(45.5)$ & $51(25.1)$ & & $15(38.5)$ & $61(27.9)$ & \\
\hline
\end{tabular}

*Self-reported, data missing in six cases

**Self-reported, data missing in four cases

***Having a history of pregnancy, including those resulted in ectopic pregnancy or miscarriage

positive. The correlation coefficient for $C$. trachomatis MIF titers and TroA IgG levels was 0.302 (for TFI patients 0.555 and for controls 0.250 ). For HtrA IgG, the correlation coefficient was 0.336 (for TFI 0.570 and for controls 0.291). All correlations were significant at the level 0.01 . Correlations between $C$. pneumoniae antibodies and TroA or HtrA antibodies were not significant $(0.053(p=0.40)$ for TroA and $0.079(p=0.21)$ for HtrA).

\section{Discussion}

We studied antibody responses against two $C$. trachomatis proteins, TroA and HtrA, expressed during persistent $C$. trachomatis infection, among subfertile women. Serum antibodies to TroA and HtrA were more common in women with TFI than in subfertile women with another cause for subfertility. Furthermore, seropositivity rates and the
Fig. 2 TroA and HtrA seropositivity increases by severity of tubal damage

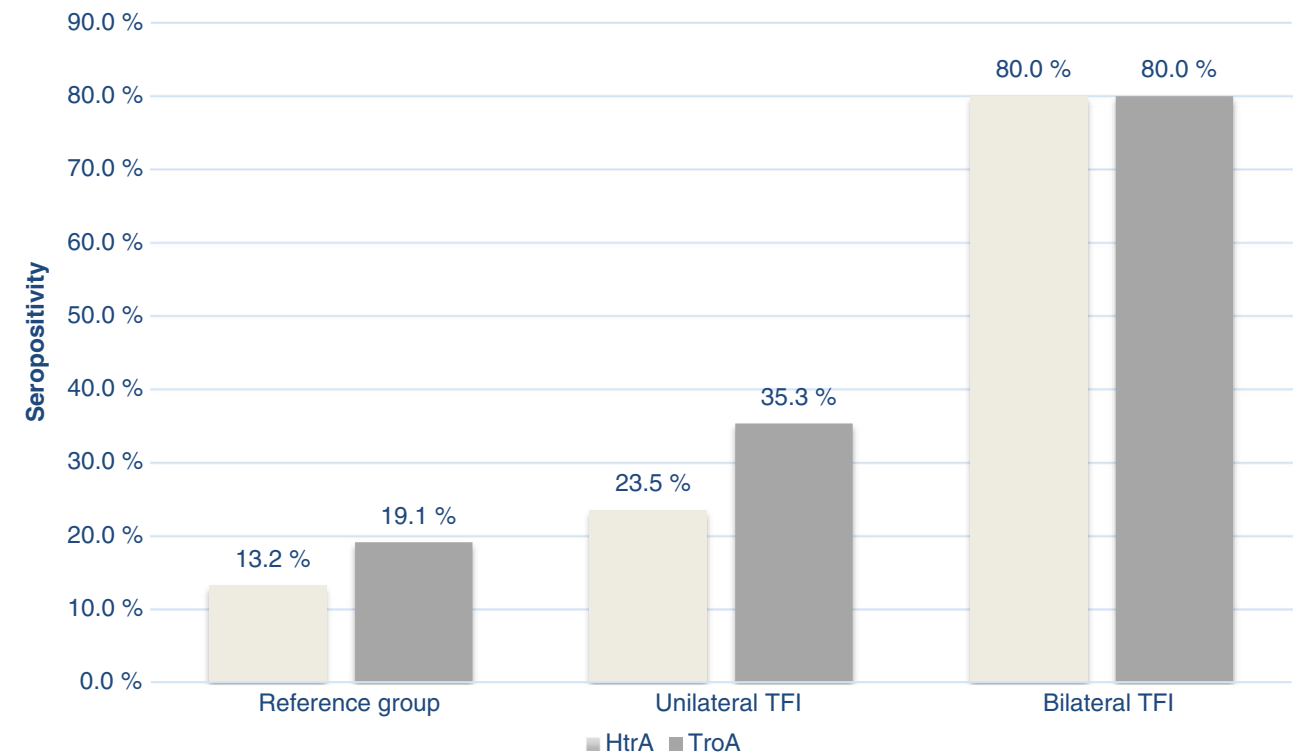


absorbance levels of TroA and HtrA antibodies increased with increasing severity of tubal damage.

To the best of our knowledge, this is the first study on serum antibody responses against $C$. trachomatis TroA and HtrA in subfertile women. Our results are in line with a previous study by Stansfield et al. who suggested that HtrA could be used as a potential biomarker in distinguishing women with C. trachomatis sequelae (TFI, EP, and PID) from those with history of single infection or multiple uncomplicated infections [11].

Microimmunofluorescence serology (MIF) has been considered the gold standard in the serological diagnosis of $C$. trachomatis, but the presence of antibodies does not distinguish past exposure and clearance of infection from persistent infection which increases the risk of TFI. In our study, a moderate correlation was found between TroA and HtrA antibody EIA absorbance levels and MIF $C$. trachomatis antibody titers. This is plausible, since TroA and HtrA antibody tests detect conditions for which serological marker or laboratory reference method is not available.

The patency of Fallopian tubes was mainly evaluated by HSSG in our study. The weaknesses of this method include the possibility of false-positive results because of tubal spasm. However, the sensitivity and specificity of HSSG is 0.95 and 0.93 compared to laparoscopy, which is considered the gold standard for diagnosing tubal pathology [12]. Moreover, HSSG allows the visualization of ovaries and uterine cavity [12]. Another limitation of our study was the low prevalence of TFI $(8.5 \%)$. Due to the high screening activity, $C$. trachomatis infections are diagnosed and treated early before PID and associated TFI develop.

C. trachomatis TroA and HtrA serology has the potential to be used as a specific biomarker to predict $C$. trachomatisrelated tubal pathology. However, our results need to be confirmed in larger study populations. Furthermore, the development of TFI is multifactorial, and further studies on the natural history of $C$. trachomatis infection are needed.

Funding This study was supported by the Academy of Finland (including project \#128597) and by Research grants from Helsinki-Uusimaa Hospital District (TYH2013405/MP, TYH2014117/MP, TYH2015318/ MP). The funders had no role in study design, data collection and interpretation, or the decision to submit the work for publication.

\section{Compliance with ethical standards}

Conflict of interest The authors declare that they have no conflict of interest.

Ethical approval All procedures performed in studies involving human participants were in accordance with the ethical standards of the institutional research committee and with the 1964 Helsinki declaration and its later amendments. The study was approved by the Helsinki University Hospital Ethical Committee (Dnro 29/E9/07).
Informed consent All couples signed an informed consent before study participation.

\section{References}

1. Unemo M, Bradshaw CS, Hocking JS, de Vries HJC, Francis SC, Mabey D, Marrazzo JM, Sonder GJB, Schwebke JR, Hoornenborg E, Peeling RW, Philip SS, Low N, Fairley CK (2017) Sexually transmitted infections: challenges ahead. Lancet Infect Dis 17: e235-e279. https://doi.org/10.1016/S1473-3099(17)30310-9

2. Geisler WM (2010) Duration of untreated, uncomplicated Chlamydia trachomatis genital infection and factors associated with chlamydia resolution: a review of human studies. J Infect Dis 201(Suppl 2):S104-S113. https://doi.org/10.1086/652402

3. Land JA, Evers JL, Goossens VJ (1998) How to use Chlamydia antibody testing in subfertility patients. Hum Reprod 13:10941098. https://doi.org/10.1093/humrep/13.4.1094

4. Wyrick PB (2010) Chlamydia trachomatis persistence in vitro: an overview. J Infect Dis 201(Suppl 2):S88-S95. https://doi.org/10. $1086 / 652394$

5. Miller JD, Sal MS, Schell M, Whittimore JD, Raulston JE (2009) Chlamydia trachomatis $\mathrm{YtgA}$ is an iron-binding periplasmic protein induced by iron restriction. Microbiology 155:2884-2894. https://doi.org/10.1099/mic.0.030247-0

6. Huston WM, Swedberg JE, Harris JM, Walsh TP, Mathews SA, Timms P (2007) The temperature activated HtrA protease from pathogen Chlamydia trachomatis acts as both a chaperone and protease at $37^{\circ} \mathrm{C}$. FEBS Lett 581:3382-3386. https://doi.org/10. 1016/j.febslet.2007.06.039

7. Marsh JW, Ong VA, Lott WB, Timms P, Tyndall JD, Huston WM (2017) CtHtrA: the lynchpin of the chlamydial surface and a promising therapeutic target. Future Microbiol 12:817-829. https://doi. org/10.2217/fmb-2017-0017

8. Hokynar K, Korhonen S, Norja P, Paavonen J, Puolakkainen M (2017) Antibody to Chlamydia trachomatis proteins, TroA and HtrA, as a biomarker for Chlamydia trachomatis infection. Eur J Clin Microbiol Infect Dis 36:49-56. https://doi.org/10.1007/ s10096-016-2769-7

9. Gaydos CA, Quinn TC, Willis D, Weissfeld A, Hook EW, Martin DH, Ferrero DV, Schachter J (2003) Performance of the APTIMA Combo 2 assay for detection of Chlamydia trachomatis and Neisseria gonorrhoeae in female urine and endocervical swab specimens. J Clin Microbiol 41(1):304-309. https://doi.org/10.1128/ JCM.41.1.304-309.2003

10. Gencay M, Koskiniemi M, Ämmala P, Fellman V, Närvänen A, Wahlström T, Vaheri A, Puolakkainen M (2000) Chlamydia trachomatis seropositivity is associated both with stillbirth and preterm delivery. APMIS 108:584-588. https://doi.org/10.1034/j. 1600-0463.2000.d01-101.x

11. Stansfield SH, Patel P, Debattista J, Armitage CW, Cunningham K, Timms P, Allan J, Mittal A, Huston WM (2013) Proof of concept: a bioinformatic and serological screening method for identifying new peptide antigens for Chlamydia trachomatis-related sequelae in women. Results Immunol 3:33-39. https://doi.org/10.1016/j. rinim.2013.05.001

12. Maheux-Lacroix S, Boutin A, Moore L, Bergeron ME, Bujold E, Laberge P, Lemyre M, Dodin S (2014) Hysterosalpingosonography for diagnosing tubal occlusion in subfertile women: a systematic review with meta-analysis. Hum Reprod 29:953-963. https://doi. org/10.1093/humrep/deu024 